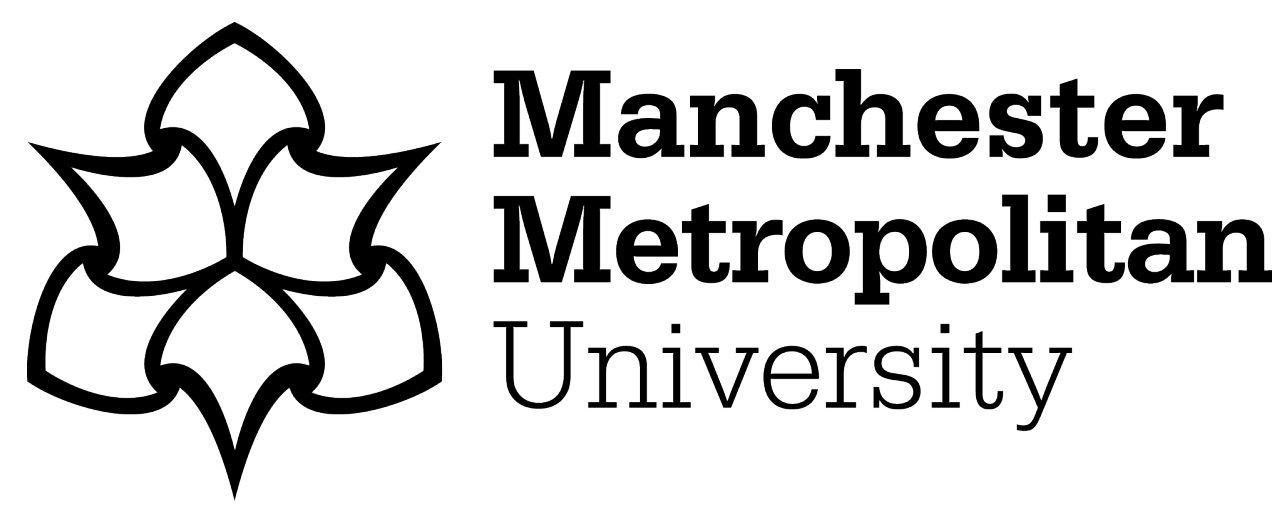

Suzanne Zeedyk, M, Davies, Cliff, Parry, Sarah ORCID logoORCID: https://orcid.org/0000-0002-5666-1997 and Caldwell, Phoebe (2009) Fostering social engagement in Romanian children with communicative impairments: the experiences of newly trained practitioners of Intensive Interaction. British Journal of Learning Disabilities, 37 (3). pp. 186-196. ISSN 1354-4187

Downloaded from: https://e-space.mmu.ac.uk/626191/

Version: Accepted Version

Publisher: Wiley

DOI: https://doi.org/10.1111/j.1468-3156.2009.00545.x

Please cite the published version 


\section{Fostering social engagement in Romanian children with communicative impairments: the experiences of newly trained practitioners of Intensive Interaction}

M. Suzanne Zeedyk, University of Dundee, School of Psychology, Dundee DD1 4HN, UK. (E-mail: m.s.zeedyk@dundee.ac.uk), Cliff Davies, University of St Andrews, School of Psychology, St Andrews KY16 9JP, UK, Sarah Parry, School of Medicine, University of Manchester, Manchester M13 9PL, UK and Phoebe Caldwell, Beechstones Barns, Mt Pleasant, High Bentham, Lancaster LA2 7LA, UK

- This article describes the benefits of using an intervention technique called 'Intensive Interaction' to make connections with children who are socially withdrawn because of communicative impairments.

- It summarises the accounts of 12 new trainees who used the technique while working as volunteers with abandoned, special needs children living in state care in Romania.

- The comments of the volunteers showed that they could identify improvements in the children's communicative abilities once they began to use Intensive Interaction. For example, the children looked at them more often, they were calmer, and they were more likely to turn the interactions into games.

- The volunteers' comments also made it clear that they felt closer to the children as a result of these changes in the interaction style.

- These results are encouraging, because they suggest that practitioners can be trained in the basics of Intensive Interaction quickly and at a low cost, enabling them to reach children who often have trouble connecting to other people.

Within the special needs field, interactive interventions are gaining attention as a means of promoting social engagement for individuals with communicative impairments. The present paper examined the experiences of practitioners of one such approach, Intensive Interaction (II), by analysing written reflections provided by 12 newly trained practitioners. Their insights are particularly interesting because they were working in a voluntary capacity with a novel population: Romanian children living in state care, whose communicative impairments have been complicated by a history of neglect. A thematic analysis indicated that one hour's training in II was sufficient for (i) enabling trainees to identify key changes in children's engagement (e.g. increased attention to partner, decreased distress) and 
(ii) strengthening trainees' sense of connection to the children. If such brief training sessions are effective in improving communicative interactions, this offers benefits to health and education service providers seeking to implement communicative intervention programmes. While interactive approaches have potential in all regions, they may be particularly valuable in countries such as Romania, which face monumental financial challenges in improving standards of childcare.

\section{Keywords Communicative neglect, Romania}

Over the past decade, the intervention of Intensive Interaction has gained attention as a means of enhancing the social abilities of individuals with severe communicative impairments. It provides a good example of what has come to be known in the fields of special needs education (Garner et al. 1995; Nind 2000) and multiple sensory impairment (e.g. Nafstad \& Rodbroe 1999; Van den Tillart 2000) as an 'interactive' or 'reciprocal' approach. Much of the recent literature on Intensive Interaction has been successful in expanding its evidence base and theorising its effectiveness for 'clients' (e.g. Caldwell 2006; Irvine 2001; Nind \& Kellett 2002; Zeedyk et al. 2009). The focus of the present paper was, in contrast, the experiences of practitioners. We aimed to add to the existing body of literature through two novel elements: (i) the reflections of newly trained practitioners, and (ii) its use with a novel client group: Romanian children with developmental abnormalities living in state care.

The technique of Intensive Interaction (II) originated within the UK in the 1980s, developed initially by Ephraim (1986) and subsequently extended by Nind \& Hewett (1994, 2001), who are now regarded as leading theorists on the approach. Their work focused on multiple and profound learning disabilities. Other theorists have extended the practice of II to new domains, such as autism (Caldwell 2004, 2006) and dementia (Astell \& Ellis 2006). The theoretical and practical base of II is informed by knowledge about the nature of parent-infant communication (e.g. Beebe et al. 1985; Stern 1985; Trevarthen 1978), in which sensitive, reciprocal responses from a caregiver are seen as the foundation for inter-personal skills. The central aim of II is to establish rapport with partners, by using their own movements and behaviours in a matched, responsive manner. Theorists explain the effectiveness of II as a result of the familiarity of those actions, which renders them neurologically and psychologically meaningful to the partner, thereby creating the joint context necessary for communicative exchanges (Caldwell 2004, 2006).

II resonates with other interactive approaches, such as Cocreative communication (Hart 2006; Nafstad \& Rodbroe 1999), Reciprocal Imitation Training (Ingersoll \& Schreibman 2006), and Floor Therapy (Greenspan \& Wieder 1997).
All of these approaches share the principles of reciprocal, client-led behaviours, and a holistic focus on the meaning of those behaviours for an individual. Empirical evaluations of II confirm that it rapidly increases engagement with a partner, via behaviours such as eye contact, emotional expression, and proximity, and that these changes can be maintained over time (e.g. Leaning \& Watson 2006; Nind 1996, 1999; Watson \& Fisher 1997; Zeedyk et al. 2009). Particular attention has been drawn to II's effectiveness in quickly reducing stereotypies and distressed behaviour (Caldwell 2006; Nind \& Kellett 2002; Samuel \& Maggs 1998).

The present study emerged out of the efforts of a NGO (non-governmental organisation) working with special needs children living in state care in Romania. The children have been orphaned or abandoned by parents, usually as a consequence of poverty and fears of developmental or medical abnormalities (e.g. autism, learning disabilities, blindness, as well as physical handicaps, HIV, or facial abnormalities). While the Romanian government has taken considerable steps to improve the standard of care afforded to abandoned children, many areas of the country are still experiencing severe difficulties in providing an appropriate level of care. The lack of training available to staff means that existing organic developmental abnormalities are often exacerbated (Dickens 2002; Gloviczki 2004; Jerre 2005; Muller \& Klich 2002). II is well suited to many of the socio-behavioural challenges presented by such children, given that they frequently exhibit symptoms of what has come to be known as 'institutional autism' (Federici 1999; Rutter et al. 2001; Spitz 1945), including severe social withdrawal, an absence of linguistic skills, obsessional stereotypies, and frequent self-harming or aggressive behaviour. We therefore expected that II would benefit this population of children, although it is to our knowledge the first time that the approach has been tried in either a Romanian setting or a special needs orphanage.

The NGO collaborating in this study, Life Improvement for Everyone (LIFE), operates by sending UK volunteers (aged 16 years or over) to developing countries, including Romania, to work intensively with disabled children for 2-week periods. They provide one-to-one attention and play, experiences that are largely lacking in the children's 
lives, given the low ratios of staffing. They are not trained in specialist intervention techniques, but are simply encouraged to play as affectionately and spontaneously with the children as possible. Volunteers report a high level of personal fulfilment as a result of their interactions with the children, and a sense of satisfaction in the funds that they have raised for LIFE and the cause it addresses.

In the present study, we took advantage of this setting to train the volunteers in the basic precepts of II, so that this could be incorporated into their methods of working with the children. None had previous familiarity with or training in the approach. We simply gave them a brief training session in II (of one hour's duration), and then encouraged them to try it with the children. This training format fits within the range of approaches that have now been developed to introduce II to care staff, professionals, and parents, including books (e.g. Caldwell 2004; Nind \& Hewett 1994, 2001), video instruction materials (e.g. Caldwell 2002, 2005; Hewett 2006), large group seminars (Partners in Policymaking, 2006), one-to-one training sessions (Caldwell 2002; : ONeill 2006), and multi-session curriculum programmes (e.g. Coia \& Jardine Handley 2008; Nind \& Hewett 1994, 2001). The fact that outcomes of these various approaches have rarely been systematically compared highlights the need for investigations such as the present one. The training approach we adopted here combined the strengths of small group seminars with video materials, in an intensive hour-long training session. Our approach was influenced by the tight time and organisational constraints operating in this initiative, and one of the aims for the data gathered in this study was to try to determine the extent to which volunteers found such brief training to be helpful to them.

We have reported elsewhere on the effectiveness of this initiative for the children involved (Davies et al. 2008). In that paper, we used quantitative, microanalytic observational techniques to code videotapes of interactions between the children and volunteers. The children's levels of social engagement with volunteers were measured before introducing II and then compared with their engagement during II sessions. The results showed that children spent significantly longer looking at their partners when II was being used than when it was not, thus confirming that II was effective in promoting social engagement. The effectiveness of II for other social behaviours exhibited by the children, such as proximity, emotional state, and activity levels, is currently being analysed.

The aim of the present study was to shift the focus away from the children's behaviour and to look more deeply at the experiences of the volunteers. Such reflections are valuable for the growing community of staff and carers who are interested in adopting interactive approaches, and our focus on new trainees augments those studies that have investigated the experiences of more experienced practitio- ners (e.g. Leaning \& Watson 2006; Nind 2000; Williams \& Wishart 2003). After several days' experience with II, we asked the volunteers to write an account reflecting on their experiences of using the approach. The technique of thematic analysis (Hayes 1997) was then used to identify common themes that emerged spontaneously within the volunteers' accounts. We were particularly interested in understanding more about their perceptions of two dimensions: (i) those pertaining to the children - what changes (if any) did they report noticing in the children's behaviour; and (ii) those pertaining to themselves - what impact (if any) did they perceive II to have had on their own confidence or motivation in relating to the children. Focusing on both dimensions accords with the philosophy underlying interactive approaches, which is that, when mutually communicative relationships are established, both 'client' and 'practitioner' are changed.

\section{Methods}

\section{Participants}

Participants were 12 young people (aged 16-19 years; nine women and three men) who were working as volunteers with LIFE for a 2-week period. All volunteers were British and lived full time in the UK; one spoke Romanian at a very minimal level. All participants had some prior experience with special needs children, although none were familiar with the technique of II before participating in this initiative. Four were visiting Romania for the first time; the remainder had been involved in a LIFE visit on at least one previous occasion.

\section{Intervention settings}

The role of the volunteers during their visit is to provide one-to-one attention to a target group of children (which numbered 18 on this visit). They interact daily with the children, following a schedule, during this visit, of morning sessions spent with the children in the day care centre they attend and afternoons spent with them in the care facilities in which they live. These are apartments housing six to eight children, supervised by approximately two careworkers. Termed 'family type homes', this model of care is now regarded as the preferred one for children in Romanian state care, with strenuous efforts being made by the government to decrease the use of large institutions (Dickens 2002).

The 18 children (10 girls, eight boys) affiliated with the present study ranged in age from approximately 4-15 years (birthdates were generally unknown to staff at the centre), and had been attending the specialist daycare facilities between 6 months and 5 years. No standard developmental inventories or diagnoses were available for the children 
(although we hope to be able to carry these out in future). All of the children displayed some degree of social withdrawal and communicative impairment, most at an extreme level, with only three exhibiting any form of spoken language. Most engaged in some amount of self-harm (e.g. biting their hand, scratching their face or body, banging their head, or pulling their hair) or self-stimulation (e.g. rocking, screaming, clapping), again often to an extreme degree. A large number had trouble feeding themselves or walking in an upright position, and some seemed to have been sedated. Although such diversity within a sample can create problems for specifying the effectiveness of an intervention approach, it is of less concern for the present study, as our focus here was on the experiences of the volunteers, rather than evaluating outcomes for the children. Such a sample is also ecologically valid for the Romanian setting, as care facilities require coping with such a diversity of difficulties.

\section{Intervention training}

The approach of II focuses on interacting with a person by using their own sounds and movements. The 'practitioner' partner observes very intently what their 'client' partner is doing, and then joins in, using the same movements, vocalisations, and rhythms. It is essentially a process of immersing one's self in the body and facial language of the other. The aim is to respond to, rather than simply to imitate, the partner's interests, concerns, and behaviours, and for the partner to come to recognise the practitioner's actions as a response. Caldwell's $(2004,2006)$ explanation why such matched responsiveness should have a powerful effect on a client's ability to engage with other people is that the brain recognises the actions as familiar and meaningful, and this allows the person to interpret them differently from non-familiar stimuli. It is for this reason that Caldwell describes the process as essentially 'learning to speak the other's language'.

Training the volunteers in II commenced mid-way through the first week, after they had had several days to get to know the children and had been filmed interacting with them in a 'standard' fashion. The tight time deadlines and hectic conditions under which we were operating led us to develop a brief, intensive approach to training. We met with the volunteers on two occasions, each lasting approximately $30 \mathrm{~min}$. The first session involved the entire group of 12 volunteers, during which the background and aims of II were explained, and a general description of the practice of II given. The volunteers were then broken into two smaller groups and shown clips from videos that illustrate II being used with special needs children and adults in the UK (e.g. Caldwell 2005). We then asked them to try to use II in their subsequent interactions with the children. Those intervention sessions were filmed, to be later coded and compared with the earlier standard sessions (now reported in Davies et al. 2008).

\section{Ethics}

The wider study examining the effectiveness of II was approved by the Research Ethics Committee of the Department of Psychology at the University of Dundee, and consent for filming the children was given by the director of the day care centre that the children attended during morning sessions. All volunteers in the present study gave their informed consent for participation, both in terms of subjecting their written reflections to qualitative analysis and also to being filmed (although that aspect of the study is not reported in the present paper).

\section{Written accounts of Intensive Interaction}

At the end of the week during which they had received training, the volunteers were asked to provide written accounts of their experience of II. No specific instructions were given about the form their comments should take, other than encouraging them to describe behaviours they had observed in the children over the week and to reflect on their personal experience of using II. Accounts were supplied by all 12 volunteers, ranging between 250 and 750 words in length. Some volunteers had chosen to focus on a single child in their comments $(n=3)$; others commented on two or three children with whom they had direct experience $(n=7)$; and the remaining volunteers $(n=2)$ commented on as many as 12 children with whom they had worked or observed other volunteers working. All 18 children in the target group featured at least once in the set of reflections.

\section{Analytic approach}

The content of volunteers' accounts was examined using the qualitative approach of thematic analysis. This approach identifies recurrent motifs or themes within a narrative data set (Hayes 1997). The process involves repeated readings of the texts, with the aim of identifying possible themes and then items pertaining to each theme. This process was undertaken by two independent coders, with disagreements resolved through discussion, followed by development of the final formulations of each theme, and then a re-coding of the data set to identify and classify all items. The aim was to identify all themes relevant to the two dimensions of interest in the study: perceived impacts of II on the children and on the volunteers themselves.

As summarised in Table 1, a total of six themes emerged. We calculated two distributions for this set of themes: (i) the number of volunteers providing comments related to each 
Table 1 Themes emerging within the narrative data set

\begin{tabular}{|c|c|c|}
\hline Theme & $\begin{array}{l}\text { Number of } \\
\text { volunteers } \\
\text { (out of 12) } \\
\text { providing } \\
\text { comments } \\
\text { within theme }\end{array}$ & $\begin{array}{l}\text { Number of } \\
\text { children } \\
\text { (out of 18) } \\
\text { represented } \\
\text { in set of } \\
\text { comments }\end{array}$ \\
\hline \multicolumn{3}{|l|}{ Impact of II on children } \\
\hline Increase in social engagement & 12 & 18 \\
\hline Decrease in distress and self-harm & 8 & 7 \\
\hline Attention to the wider environment & 4 & 4 \\
\hline \multicolumn{3}{|l|}{ Impact of II on volunteers themselves } \\
\hline $\begin{array}{l}\text { Intensified relationships with } \\
\text { the children }\end{array}$ & 11 & - \\
\hline Ineffectiveness & 4 & - \\
\hline Initial doubts & 6 & - \\
\hline
\end{tabular}

theme, and (ii) where relevant, the number of children represented within a theme. While the primary aim of thematic analysis is to identify thematic categories emerging within a narrative data set, our calculation of these distributions demonstrates the frequency of their occurrence. In the analysis that follows, a subset of up to three items will be provided to illustrate each theme. Items were selected for inclusion in the paper on the basis that each subset contained quotes representing different volunteers and different children, thus providing as representative a subset as possible of the larger set of items. Anonymity of children was preserved through the use of pseudonyms, and anonymity of participants preserved through the use of numeric identifiers.

\section{Results}

\section{Perceived impact on the children}

Increase in social engagement

All 12 of the participating volunteers reported observing increases in the children's social engagement. They cited four types of behaviour as evidence of this shift, as discussed below.

The most frequently cited behaviour was an increase in the children's attention to their partner.

Flavius is fixated with his hands, and constantly holds them in front of his eyes, moving them in a certain way, particularly when he is excited or distressed. I knelt in front of him and copied his hand movements in front of my own eyes. Flavius saw what I was doing and turned towards me. He looked excited and began to do the action more animatedly, watching what I was doing at the same time, and it really felt like we were having a type of conversation. I found this remarkable, as I had found it difficult to engage with Flavius. After about $20 \mathrm{~s}$ of this 'conversation', he got up and jumped into my arms. [7]

To my surprise, after a few minutes of persistence, Alina was facing me and her sounds were becoming notably more pronounced. Her interaction with me was more personal and it appeared that she was less distracted by her surroundings. [10]

After (starting to use Intensive Interaction), Ramona would approach me at various times, holding my face and anticipating the blowing of raspberries, which she loved. She would concentrate on people for longer periods of time than before. [4]

A second behavioural indicator observed by volunteers was an increase in the amount of positive affect displayed by the children.

Brindusa and I began to have a conversation with the sound 'aah'. I would wait for her to say it, and then I would respond. I developed this into a sort of anticipation game where sometimes I would on purpose not say anything, in order to tease her. This resulted in her getting really excited and trying to force my mouth open into an 'aah' shape. She absolutely loved this game and every time I would give in and eventually say 'aah', she would give me the tightest hug and laugh. [3]

I started by just imitating Paula's actions for a few minutes, such as moving my head in motion with hers and twiddling with the grass. Then I introduced sounds. Soon after I found that she had moved slightly closer to me and was smiling more than she had before. Over the next $10 \mathrm{~min}$ of imitation, she was right next to me and put her hand in my lap, allowing me to stroke her hand and was smiling and even giggling, which I haven't really seen her do before. [2]

One thing that I found worked very well with Monica was my imitating the shape in which she held her hand, with my hand. It made her laugh. She laughed each time I held my hand in this way. [7]

Greater proximity to others constituted a third means by which volunteers perceived the children's engagement to have increased.

I imitated Madalina's vocalisations and she focused on me longer than she had done before trying Intensive Interaction. She then moved much closer to me and reached across to me and allowed me to hug her. [2]

Mariana is an extremely shy girl, and I initially found it difficult to gain her trust. She would just sit facing the wall and sucking her thumb, or would walk 
around by herself eating grass. I began to imitate Mariana by pretending to pick and eat grass as she did, and I copied the noises she made as she ate the grass. After a short amount of time, she jumped into my arms. [7]

Monica makes positions with her fingers. These seemed a perfect opportunity to try Intensive Interaction. Monica noticed my imitation of her hands almost immediately, and would change them as if testing my ability to copy her. These short sessions of hand imitation would almost invariably result in her touching or taking my hand. [6]

Finally, increased flexibility and ease in interactions seemed to present a particularly emotive indicator of increased engagement.

After imitating Nela, which was extremely difficult as she has no particular habits, she became more attached to me and allowed us to do an activity that I suggested, rather than just doing everything that she wanted us to do. [1]

The imitation games made Brindusa seem a lot more comfortable with me, a lot more responsive, and extremely interested in me. In general, she was a great deal more happy and affectionate. [3]

Today has been amazing. The clapping game was so much fun. I imitated Andrei, via clapping in different rhythms and also clapping around him, not just the way he prefers to. It means it does feel you are having a conversation with him, or playing a game. [11]

This signal may have been so significant for the volunteers because increased flexibility permitted the spontaneous creation of new games and routines. These games always included elements introduced by the children. A detailed example of such games included the following:

Anton began to encourage me to play certain games, in which I was imitating him... In one game, he would hold up a ball until I held up a ball of the same colour, and would watch me intently so that we would both drop our balls at the same time. In another game, Anton picked up one of his socks and gave me the other, so I could imitate what he did with his sock, and this brought great joy to him. [7]

The creation of such games was made possible through two particular elements that the volunteers described the children themselves as introducing into the interactions. The first of these was testing or teasing, introduced by a child as if he/she wished to make sure that this new partner could be trusted to 'really get it right'.
It was as if Madalina was playing a game with me....I imitated her rocking and she would change her rocking speed to see if I changed mine to stay in motion with her. [2]

I found that Anton was testing me to see if I followed his movements. [4]

Roxana is a very frightened and untrusting girl, who is difficult to engage with and who often lashes out violently at the other children and staff at the centre. She often rocks back and forth in frustration, so I decided to stand next to her and imitate her rocking. When she noticed me doing this...the rocking then turned into a sort of a game, with Roxana purposely rocking in different ways, her watching me imitate her, and her smiling with enjoyment. [7]

The second element of the new games involved the child imitating the adult's actions, as if to demonstrate that he/she fully understood how this new game was played.

Stephan saw me imitating one of the other children and wanted to join in. He got two plastic skittles and wanted me to 'copy' him. He also started imitating my movements, which seemed to me to be showing his intelligence. [4]

Now Ion and I are able to create games out of imitation. He walks behind me, copying my walk, in fits of giggles. Whenever this happened it made playing with him so much more enjoyable. [9]

Beatrice has a tendency to stand by herself and do nothing. On a couple of occasions I imitated her mouth, head, and hand movements. This caused her to look at me, and to go on to imitate my own hand movements. I had previously been unable to encourage her to engage with me at all. [7]

Overall, these outcomes identify a range of behavioural shifts that were spontaneously observed by newly trained practitioners. This pattern of increased engagement appeared to be widespread, as it was described for all 18 children in the target group (100\%), and also swift, as the period over which changes were described as occurring was usually a matter of minutes or even seconds. Ultimately, the volunteers found their exchanges with the children to have become more creative, elaborate, and communicative after the introduction of II.

\section{Decrease in distress and self-harm}

A second outcome notable in the volunteers' accounts was a reduction in children's distress and self-harm. Eight of the 12 volunteers described observing such decreases. 
I had found being around Anton extremely hard (because he spends so much time hitting himself on the head). I even cried while attempting to interact with him. I'd spend half the time anticipating him banging his head and the other half trying to think about what situation would have made him like that. And then thinking about the fact that so many children in the centre harm themselves just became overwhelming. But then I saw imitation being used with Anton and it was working really well. The head banging had decreased and he was much more focused on what he was doing. Later, I tried it with him myself, and for the whole period of time I was with him, even though that was short, he didn't bang his head. [4]

The next day, Mircea was restless and agitated. This upset me a lot more than I thought it could. I think this was because we had connected so well the day before, and I felt useless being unable to comfort him. Then I got reminded to try and use Intensive Interaction, even when he was unhappy, and I managed to calm him down enough for him to fall asleep and snore on me. I made me feel much better knowing that I can comfort him by imitating. [5]

Ion frequently throws fits, where he will shout and bang his feet on the floor. I tried many different strategies in hope of getting him to calm down: I gave him a hug, I told him to stop it, I picked him up. However, I found that imitating his shouting and feet stamping was by far the most effective tactic at calming Ion down. [7]

Overall, as shown in Table 1, a decrease in distress was spontaneously reported for seven of the 18 children attending the centre $(39 \%)$, thereby suggesting that such shifts tended to be easily perceptible by these new practitioners.

\section{Attention to the wider environment}

Another theme that was discernable in the reflective accounts was an increased interest that the children showed in their wider environment. Four of the volunteers described observing such shifts, with each description pertaining to a different child (22\% of the group of 18$)$.

I've seen progression even today - Serghei found an alternative toy to play with: the hula hoop. He had great fun, as indicated by the smile on his face. [12]

By the end of the week, Flavius actually picked up a toy from the grass, and I've never seen him do that. [4]

When we took the children to the park later that day, Madalina interacted with another child in the park, which is something neither me nor her carers had ever seen her do before. I believe this was due to the Intensive Interaction we had been trying, that it increased her interaction with others. [2]

Although descriptions of this type of shift were less frequent than the previous two themes, it is notable that behaviours which are not directly related to social engagement (which is the primary focus of II) should have caught the attention of even some of the group of volunteers. They clearly perceived the children's wider attention to be significant, as evidenced in their comments of having 'never before' observed such interests.

\section{Impact on the volunteers themselves}

\section{Intensified relationships with the children}

In their accounts, the volunteers described how changes in the children had affected them personally. All but one of the participants $(n=11)$ commented, at some point in their reflections, on ways in which II had intensified their relationships with the children.

It was really satisfying to see such a reaction in a little girl who usually wanders about eating grass. She was looking at me, checking I was there, and communicating with noises. After the morning session, it felt like I had made a real contribution in making Ramona's day much more enjoyable. [5]

I had such a special morning with Brindusa when I introduced imitation into our play. [3]

I have fallen in love with Andrei, and it feels that he has a connection with me also. Instead of feeling that there is a lack of energy in me to keep chasing him as he attempts to escape, or the boredom of clapping to the same rhythm, or watching him bite his hand and grind his teeth, which is painful for me to watch, I now think that Andrei isn't that hard to work with and that he doesn't necessarily require more than one person. [11]

Even minimal experience with II was sufficient to engender significant emotional shifts for these volunteers. This provides a reminder of the extent to which a practitioner's motivation is related to the bond that they feel they have with their 'client' partner. Such commitment is important in sustaining the capacity to work with people who present severe behavioural difficulties.

\section{Ineffectiveness}

Four participants also described instances in which they felt uncertain about their effectiveness in employing II. 
I spent a bit of time with Alina, singing and pointing at the TV in the same way as her. She seemed to enjoy this very much, although I'm not sure if it was the imitation she enjoyed or just the singing to herself. [1]

I also tried imitating Stephan's actions, such as the biting of his hand when he's frustrated, and his rocking on his back when he's upset. Unfortunately, I had less success with this. [3]

I have observed improvement in Ovidiu's behaviour and progression when it comes to verbal communication. Perhaps this could be due to some extent to the imitation technique? [12]

Such comments, even from only a small proportion of the participants, are encouraging, for their presence mediates the risk that the larger set of positive reports obtained in this study could be attributed simply to experimenter demand. Volunteers did observe effects other than those that they 'expected' to see, and were willing to report these instances of apparent failure. Such comments also suggest that moments of uncertainty are part of the process of learning to use II.

\section{Initial doubts}

Finally, it is interesting to realise that the positive outcomes experienced by participants were often ones that they had not anticipated. Half the participants $(n=6)$ commented spontaneously on doubts that they had originally held about the technique of II.

What we've been introduced to this week is amazing. Everything that we were told did work, although I had had doubts. My opinion has completely changed. I feel like I've been witness to something special and am very grateful to have had that opportunity. It will make saying goodbye to the children really hard, though. [4]

I truly cannot believe how amazing the results of the technique have been. [3]

I didn't really expect Intensive Interaction to work with Serghei because he seemed so distant and impossible to reach. I was surprised when it did work so well. [8]

The 'amazement' so frequently described in the volunteers' accounts seems to contain within it more than the satisfaction that comes from (finally) communicating successfully with another person. There is a sense that these volunteers are deeply surprised at how easily this 'simple' form of response seems to unlock the door of these children's previously isolated worlds.

\section{Discussion}

The results of this study indicate that even brief training in Intensive Interaction (II) has the capacity to alter the way that practitioners experience their interactions with partners who have severe communicative impairments. All trainees reported observing increased engagement in the children with whom they were working, and they also commented on the stronger motivation and sense of connection they personally felt. Such findings are valuable because they concur with those from other studies investigating outcomes of II for both practitioners (Leaning \& Watson 2006; Nind 2000) and clients (Nind 1999; Watson \& Fisher 1997; Zeedyk et al. 2009, while extending them to a new population: children whose communicative impairments are exacerbated by a history of neglect.

The change that seems to occur in practitioners' motivation, as a result of implementing an interactive approach, is striking. Nind (2000), p. 194) has previously described it as 'transformative', attributing this to a combination of intuitive fit and effectiveness. II serves as a kind of tool for practitioners, assisting them in developing a communicative style that is more equitable and spontaneous; in return, partners are perceived as becoming more responsive, calmer, and curious. Several investigations of interactive interventions have now commented on the intensity of feeling that practitioners experience as interactions shift (e.g Garner et al. 1995; Hewett \& Nind 1998; Williams \& Wishart 2003), but these have tended to focus on experienced practitioners. The present findings reveal that this intensity emerges early within the period of skills development, and does not require extensive experience with II. The fact that half of the volunteers expressed initial doubts about the likely effectiveness of II also suggests that practitioners do not have to be convinced of II's value prior to 'trying it out'. Insights such as these are useful for the field, given that nurturing practitioners' motivation enables them to remain engaged in what can be a difficult task. As one student in this study expressed it: 'Until we were taught about this technique, I had no idea how I was going to last 2 weeks with this unresponsive little boy. Now everything has changed - for him and for me.'

The behavioural changes noted by the volunteers are interesting in that they resonate with the larger literature on II. Four key behaviours featured in volunteers' reflections: attention to partner, positive affect, proximity to others, and flexibility of interaction. These four behaviours have both empirical and theoretical correspondence, in that they are amongst those that have been scrutinised in observational studies (e.g. Leaning \& Watson 2006; Nind \& Kellett 2002; ONeill 2006; Zeedyk et al. 2009) and also those for which II theorists would predict change (e.g. Caldwell 2006; Nind \& Hewett 1994). Such correspondence lessens concerns that 
the volunteers' reported perceptions of II might have been unduly biased by the training they had received. It is inevitable that training will shape practitioners' expectations of an intervention to some extent, for that it is the purpose of training. Using multiple evaluation methods (a process often referred to as 'triangulation') can offer a broader perspective on outcomes. It is thus encouraging that the narrative reports given by the volunteers correspond with the behavioural observations we previously reported for this sample, which confirmed that the amount of children's eye gaze to partners did indeed increase with II (Davies et al., 2008). Both external observers and practitioners saw the same kinds of changes occurring in the children's behaviour.

In future, the field would benefit from carrying out comparisons of the variety of training approaches that have now been developed for II. Formal course-based methods (e.g. Coia \& Jardine Handley 2008; Nind 2000; Nind \& Hewett 1994) provide theoretical depth and complexity, but require a considerable time investment. Informal training methods (e.g. videos, books, one-to-one training sessions, and the group training session utilised here; Caldwell 2006; Hewett 2006) may be quicker, but risk fostering a weaker grounding in the technique. Studies could explore these contrasts at a variety of levels, including rapidity of effectiveness, confidence of practitioners, and effectiveness for different types of impairment. Future investigations of sustainability over time are of particular importance, given that while some reports have detailed improved outcomes lasting between 1 and 6 months (e.g. Ingersoll \& Schreibman 2006; Leaning \& Watson 2006; Nind \& Kellett 2002), others have reported decreases in practitioners' memory for key principles (Nind 2000). Comparative studies should be of interest to health and educational authorities attempting to implement financially viable means of working with people with communicative impairments, especially given the rise in prevalence that has occurred for conditions such as autism (Chakrabati \& Fombonne 2001). Such interest should be enhanced by the rapid reduction in distress that the volunteers' comments here suggest. Such impressions are currently supported by only a small number of empirical evaluations and practitioner reports (e.g. Caldwell 2006; Nind \& Kellett 2002), so more work is needed.

Comparative studies might also help to stimulate theoretical debates within the II field, for example refining what is meant by the term 'imitation'. This term was often invoked in the volunteers' accounts, and it is frequently associated with reciprocal interventions. Yet it is resisted by many II theorists (e.g. Caldwell 2006; Coia P., NHS Wakefield Trust, Sheffield, UK, pers. comm.; Nind \& Kellett 2002), because they believe that the term engenders a sense of mimicking the client, objectifying rather than valuing them as a person. These theorists also fear that the term encourages a circular rigidity within interactions (i.e. a mechanical repetition of the partner's behaviours), while their aim is to use II to foster the kind of creativity and spontaneity that is essential to genuine inter-personal interaction, such as the game playing described by the volunteers here. Yet other theorists do employ the term (e.g. Ingersoll \& Schreibman 2006), in part because it taps into a wider psychological and neuroscientific debate about the role of imitation in human functioning (e.g. Nadel et al. 1999; Rizzolatti et al., 1995; Zeedyk \& Heimann 2006). Greater attention to such conceptual debates would strengthen the potential of the II field for theoretical and clinical impact.

It is appropriate to end this paper by commenting on the particular benefits that interactive approaches may offer to those regions of Eastern Europe, including Romania, which are striving to improve their standards of childcare (Dickens 2002; Jerre 2005). Despite considerable efforts to date, which were boosted during the process of gaining admission into the European Union, these countries continue to face monumental struggles. One component is that too little training and information is available to staff about how to cope with children with learning disabilities (Conn \& Crawford 1999; Hardman 2004). This lack of knowledge has fuelled concerns that children in state care are still subjected to emotional, physical, and medical abuses (Muller \& Klich 2002). International non-governmental organisations, such as LIFE, have an important role to play in changing this situation (Gloviczki 2004). If there is any chance of expanding knowledge of intervention approaches, especially those that involve little cost and yield rapid effectiveness, then the children of Romania deserve such effort. Langton (2006) has argued that while these children have taught the field of psychology much about the appalling long-term consequences of poor early care (e.g. Rutter et al. 2001; Smyke et al. 2007), the children themselves have largely failed to benefit from this body of work. She argues that the field has a duty to serve them better in future. It is our hope that, with Romania's transition into membership of the European Union now complete, the increasing enthusiasm for interactive approaches may be but one way that psychology and related fields can fulfil this responsibility.

\section{Acknowledgements}

Gratitude is offered to the volunteers who so enthusiastically participated in this study: Nina Amini-Tabrizi, Alexandra Daly, Atul Dhupelia, Laura Heggie, Lucy Martin, Verity Pandya, Nikesh Parekh, Deepa Patel, Fabienne Rose, Adam Sturmey, Lauren Waterman, and May Wells. The directors of the day care centre 'Casa Luminii' are congratulated for the care they have provided to these children over the past several years, and thanked for the assistance they provided us in this research initiative. The organisation LIFE is to be commended for the many efforts they have 
expended to enrich the lives of children in Romania (and also Bulgaria, India, Uganda, and Belarus). Since the data were collected for the present study, the technique of Intensive Interaction has become a standard part of the practice of LIFE volunteers. More information about LIFE can be found on their website: http://www.lifeimprovement-uk.com.

\section{References}

Astell A.J. \& Ellis M.P. (2006) The social function of imitation in severe dementia. Infant and Child Development, 15: 311-9.

Beebe B., Jaffe J., Feldstein S., Mays K. \& Alson D. (1985) Interpersonal timing: the application of an adult dialogue model to mother-infant vocal and kinetic interactions. In: Field T.M., Fox N., editors. Social perception in infants, 217-247. Norwood, NJ, Ablex.

Caldwell P. (2002) Learning the language. Brighton, Pavilion Publishing.

Caldwell P. (2004) Crossing the minefield: establishing safe passage through the sensory chaos of austistic spectrum disorder. Brighton, Pavilion Publishing.

Caldwell P. (2005) Creative conversations: communicating with people with profound and multiple learning disabilities. Brighton, Pavilion Publishing.

Caldwell P. (2006) Finding you, finding me: using Intensive Interaction to get in touch with people whose severe learning disabilities are combined with autistic spectrum disorder. London, Jessica Kingsley Publishers.

Chakrabati S. \& Fombonne E. (2001) Pervasive developmental disorders in preschool children. Journal of the American Medical Association, 285: 3093-9.

Coia P. \& Jardine Handley A. (2008) Developing relationships with people with profound learning disabilities through intensive interactions. In: Zeedyk M.S., editor. Making contact: promoting social interaction for individuals with communicative impairments. London, Jessica Kingsley Publishers: 102-18.

Conn L. \& Crawford C. (1999) State child care in Romania: a University initiative to promote required change from within. Journal of Social Work Practice, 13: 83-90.

Davies C.E., Zeedyk M.S., Walls S., Betts N. \& Parry S. (2008) Intensive Interaction increases engagement in Romanian children with a history of severe neglect and communicative impairment. In: Zeedyk M.S., editor. Making contact: promoting social interaction for individuals with communicative impairments. London, Jessica Kingsley Publishers: 84-101.

Dickens J. (2002) The paradox of inter-country adoption: analysing Romania's experience as a sending country. International Journal of Social Welfare, 11: 76-83.

Ephraim G. (1986) A brief introduction to augmented mothering. Playtrack Pamphlet. Harpebury Hospital School. Radlet: Herts.

Federici R.S. (1999) Neuropsychological evaluation and rehabilitation of the post institutionalised child. Presentation at the Conference for Children and Residential Care. Stockholm. http:/ / www.drfederici.com (last accessed on 1 March 2009).

Garner P., Hinchcliffe V. \& Sandow S. (1995) What teachers do: developments in special education. London, Paul Chapman.
Gloviczki P.J. (2004) Ceausescu's children: the process of democratization and the plight of Romania's orphans. Critique: $A$ Worldwide Student Journal of Politics, Fall: 116-25. Chicago, IL, Illinois State University.

Greenspan S.L. \& Wieder S. (1997) Developmental patterns and outcomes in infants and children with disorders in relating and communicating: a chart review of 200 cases of children with autistic spectrum diagnoses. Journal of Developmental and Learning Disorders, 1: 87-141.

Hardman C. (2004) Analysing the management of challenging behaviour in Romanian orphanages: looking for ways forward. Support for Learning, 19: 38-44.

Hart P. (2006) Using imitation with congenitally deafblind adults: establishing meaningful communication in partnerships. Infant and Child Development, 15: 263-74.

Hayes N. (1997) Doing qualitative analysis in psychology. Hove, UK, Psychology Press.

Hewett D. (2006) Intensive Interaction DVD. UK, Intensive Interaction Institute.

Hewett D. \& Nind M. (editors) (1998) Interaction in action: reflections on the use of Intensive Interaction. London, David Fulton Publishers.

Ingersoll B. \& Schreibman L. (2006) Teaching reciprocal imitation skills to young children with autism using a naturalistic behavioral approach: effects on language, pretend play, and joint attention. Journal of Autism and Development Disorders, 36: 487-505.

Irvine C. (2001) On the floor and playing. Royal College of Speech and Language Therapists Bulletin, 595: 9-11.

Jerre U. (2005) The state of knowledge about child protection reform in Romania. PhD thesis. Sweden, Dept of Political Science, Lund University.

Langton E.G. (2006) Romania's children. The Psychologist, 19: 412-3.

Leaning B. \& Watson T. (2006) From the inside looking out - an Intensive Interaction group for people with profound and multiple learning disabilities. British Journal of Learning Disabilities, 34: 103-9.

Muller H. \& Klich K. (2002) Children of Ceausescu. New York, Umbrage Editions Inc.

Nadel J., Guerini C., Peze A. \& Rivet C. (1999) The evolving nature of imitation as a format for communication. In: Nadel J., Butterworth G., editors. Imitation in infancy, 209-234. Cambridge, Cambridge University Press.

Nafstad A. \& Rodbroe I. (1999) Co-creative communication. Oslo, Forlaget-Nord Press.

Nind M. (1996) Efficacy of Intensive Interaction: developing sociability and communication in people with severe and complex learning difficulties using an approach based on caregiver interaction. European Journal of Special Needs Education, 11: 48-66.

Nind M. (1999) Intensive Interaction and autism: a useful approach? British Journal of Special Education, 26: 96-102.

Nind M. (2000) Teachers' understanding of interactive approaches in special education. International Journal of Disability, Development, and Education, 47: 183-99.

Nind M. \& Hewett D. (1994) Access to communication. London, David Fulton Publishers.

Nind M. \& Hewett D. (2001) A practical guide to Intensive Interaction. Kidderminster, British Institute of Learning Disabilities. 
Nind M. \& Kellett M. (2002) Responding to individuals with severe learning difficulties and stereotyped behaviour: challenges for an inclusive era. European Journal of Special Needs Education, 3: 265-82.

ONeill M. (2006) Imitation as an intervention with children with autistic spectrum disorder and their parents/carers. PhD Thesis submitted to the University of Dundee. Dundee, UK.

Partners in Policymaking. (2006) http:/ /www.partnersinpolicy making.co.uk (last accessed on 1 March 2009).

Rizzolatti G., Camarda R., Gallese V. \& Fogassik L. (1995) Premotor cortex and the recognition of motor actions. Cognitive Brain Research, 3: 131-41.

Rutter M., Kreppner J.M. \& O'Conner T.G. (2001) Specificity and heterogeneity in children's responses to profound institutional deprivation. British Journal of Psychiatry, 179: 97-103.

Samuel J. \& Maggs J. (1998) Introducing Intensive Interaction for people with profound learning disabilities liing in small staffed houses in the community. In: Hewett D., Nind M., editors. Interaction in action: reflections on the use of Intensive Interaction, 119-148. London, David Fulton.

Smyke A.T., Koga S.F., Johnson D.E., Zeanah C. H., the BEIP Core Group et al. (2007) The caregiving context in institution-reared and family reared infants and toddlers in Romania. Journal of Child Psychology and Psychiatry, 48: 210-8.
Spitz R. (1945) Hospitalism: an inquiry into the genesis of psychiatric conditions in early childhood. The Psychoanalytic Study of the Child, 1: 53-74.

Stern D.N. (1985) The interpersonal world of the infant. New York, Basic Books.

Trevarthen C. (1978) Modes of perceiving and modes of acting. In: Pick H.L.., Saltzman E., editors. Modes of perceiving and processing information. Cambridge, Cambridge University Press.

Van den Tillart B. (2000) Encouraging reciprocity in interaction with deafblind people and their partners. Deafblind Review, 25: 6-8.

Watson J. \& Fisher A. (1997) Evaluating the effectiveness of Intensive Interaction teaching with pupils with profound and complex learning difficulties. British Journal of Special Education, 24: $80-7$.

Williams K.R. \& Wishart J.G. (2003) The Son-Rise Program intervention for autism: an investigation into family experiences. Journal of Intellectual Disability Research, 47: 291-9.

Zeedyk M.S. \& Heimann M. (2006) Introduction: imitation and socioemotional processes: implications for communicative development and interventions. Infant and Child Development, 15: 219-21.

Zeedyk M.S., Caldwell P. \& Davies C.E. (2009) Imitation promotes social engagement in adults with severe learning disabilities. European Journal of Special Needs Education, 24: 119-137. 